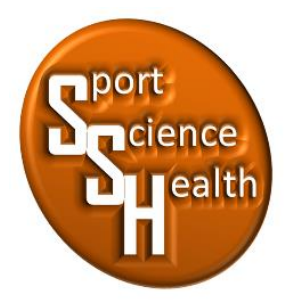

ISSN 2715-3886

\title{
Survei Gerak Dasar Lokomotor dan Manipulatif Siswa Kelas IV SD
}

\author{
Abdul Rohman Mashudi ${ }^{1 *}$, Siti Nurrochmah ${ }^{2}$ \\ 1,2Jurusan Pendidikan Jasmani Kesehatan dan Rekreasi, Fakultas IImu Keolahragaan, \\ Universitas Negeri Malang, Jalan Semarang No. 5, Malang, Jawa Timur, 65145, Indonesia \\ *Penulis koresponden: tentangbebeg@gmail.com, 085755346039
}

Artikel diterima: 7 Januari 2020; direvisi: 19 Agustus 2020; disetujui: 23 Agustus 2020

\begin{abstract}
The purpose of this study was to determine the development of basic locomotor and manipulative movements of students through the 30 meter running test, long jump without prefix, vertical jump, catch the ball and throw the ball at the goal using the target. The results of the research data on the ability of basic locomotor motion using the 30 meter running test were in the good category totaling 12 students. The ability to move long jump without prefix was in the very good category amounting to 17 students and the ability to move upright (vertical jump) was in the medium category and not good amounting to 14 students. Meanwhile, the ability of manipulative movement using the throw and catch test was in the bad category, amounting to 17 students. The ability to throw the ball at the goal using the target is in the medium category amounting to 10 students.
\end{abstract}

Keyword: locomotor and manipulative motion, basic motion

\begin{abstract}
Abstrak: Tujuan penelitian ini adalah untuk mengetahui perkembangan gerak dasar lokomotor dan manipulatif siswa melalui tes lari 30 meter, loncat jauh tanpa awalan, loncat tegak, lempar tangkap bola dan lempar bola ke gawang menggunakan sasaran. Hasil data penelitian kemampuan gerak gerak dasar lokomotor menggunakan tes lari 30 meter berada pada kategori baik berjumlah 12 siswa. Kemampuan gerak loncat jauh tanpa awalan berada pada kategori baik sekali berjumlah 17 siswa dan kemampuan gerak loncat tegak (vertical jump) berada pada kategori sedang dan kurang baik berjumlah 14 siswa. Sedangkan kemampuan gerak manipulatif menggunakan tes lempar tangkap berada pada kategori tidak baik berjumlah 17 siswa. Kemampuan lempar bola ke gawang menggunakan sasaran berada pada kategori sedang sebesar berjumlah 10 siswa.
\end{abstract}

Kata kunci: gerak lokomotor dan manipulatif, gerak dasar

\section{PENDAHULUAN}

Dalam kemajuan teknologi informasi dan komunikasi yang sudah mencapai tahap yang sangat maju telah memberikan suatu masalah terhadap bangsa kita. Budaya hidup mudah/gampang, kurang bergerak semakin kuat menggejala di kalangan anak-anak dan remaja. Dalam kondisi demikian patutlah kita pertanyakan kembali peranan dan fungsi pendidikan, khususnya pendidikan jasmani dan olahraga.

Pendidikan jasmani olahraga dan kesehatan juga bertujuan untuk meningkatkan kemampuan gerak dasar yang dimiliki oleh anak-anak. Kemampuan keterampilan gerak dasar merupakan sebuah kemampuan yang sangat penting di dalam kehidupan sehari-hari maupun dalam pendidikan jasmani olahraga dan kesehatan. 
Salah satu pemberian program pendidikan jasmani olahraga dan kesehatan kepada anak-anak adalah agar menjadi terampil dalam melakukan aktifitas fisik.

Pendidikan jasmani harus menyebabkan perbaikan dalam pikiran dan tubuh yang mempengarui seluruh aspek kehidupan keseharian seseorang (Department for Education, 2013; Mu'arifin, Kurniawan, \& Heynoek, 2018; Wallhead \& Ntoumanis, 2016). Pada dasarnya pendidikan jasmani olahraga dan kesehatan harus sudah ditanamkan sejak masih kanak-kanak karena pada umumnya jika ingin menguasai berbagai macam aktivitas, dasarnya harus diletakkan pada masa kanak-kanak dan menurut para orang dewasa kebanyakan hobi dari mereka berdasarkan pengalaman pada masa kanak-kanak.

Usia Sekolah Dasar merupakan masa-masa yang sangat menentukan pertumbuhan dan perkembangan fisik serta gerak yang memegang peranan penting dalam pembentukan individu yang berkualitas di kemudian hari.

Struktur dan kurikulum pendidikan jasmani olahraga dan kesehatan di sekolah dasar yang ada sekarang memiliki ciri-ciri yang terdiri atas keterampilan teknik dasar beberapa cabang olahraga. Keterampilan teknik dasar olahraga ini, akan dapat dikuasai bila sebelumnya menguasai keterampilan gerak dasar. Keterampilan gerak dasar di Sekolah Dasar itu dapat dibagi menjadi beberapa kategori meliputi tiga macam, yaitu: lokomotor, nonlokomotor, dan manipulatif.

Salah satu tujuan pelaksanaan pendidikan jasmani olahraga dan kesehatan di Sekolah Dasar adalah meningkatkan kemampuan keterampilan gerak dasar (Habe \& Ahiruddin, 2017; KEMENKES, 2014; Pendidikan Nasional, 2014). Pada dasarnya gerak dasar manusia adalah jalan, lari, lompat dan lempar (Krakauer, Hadjiosif, Xu, Wong, \& Haith, 2019; McKenzie et al., 2014). Bentuk gerakan dasar tersebut telah dimiliki oleh murid-murid Sekolah Dasar. Gerak dasar jalan, lari, dan lompat merupakan gerak dasar lokomotor yang perlu dikembangkan di Sekolah Dasar (SD) di samping gerak dasar lainnya.

Pendidikan jasmani olahraga dan kesehatan di Sekolah Dasar saat ini telah menggunakan kurikulum 2013, di dalamnya berisi sejumlah materi yang harus dikuasai oleh anak-anak yang terangkum dalam Kompetensi Inti dan Kompetensi Dasar (KI dan KD).

RPP menjadi panduan atau pedoman guru pendidikan jasmani olahraga dan kesehatan dalam proses kegiatan pembelajaran dan didalamnya memuat macam variasi aktivitas pembelajaran pendidikan jasmani olahraga dan kesehatan. Belum diketahuinya model pembelajaran pendidikan jasmani Sekolah Dasar Negeri 1 Andonosari menjadi salah satu faktor dilaksanakannya penelitian ini.

Berdasarkan observasi awal yang dilakukan penyebaran angket dan melakukan pengamatan ketika pembelajaran pendidikan jasmani olahraga dan kesehatan di SD Negeri 1 Andonosari kelas IV, hasil dari penyebaran angket adalah 90\% anak-anak kelas IV SD Negeri 1 Andonosari belum dapat mengetahui apa arti atau definisi dari gerak lokomotor dan gerak manipulatif sehingga anak-anak masih sangat bingung dalam membedakan kedua gerak tersebut, ditambah lagi masing-masing guru pendidikan jasmani olahraga dan kesehatan dalam mengembangkan materi gerak dasar tersebut belum berhasil, guru pendidikan jasmani olahraga dan kesehatan kurang kreatif dalam membuat variasi atau memodifikasi pembelajaran pendidikan jasmani kesehatan dan olahraga yang tepat untuk meningkatkan keterampilan gerak lokomotor dan manipulatif anak. Materi pembelajaran keterampilan gerak dasar lokomotor dan manipulatif yang dikembangkan dengan baik, akan sangat membantu perkembangan anak, terutama perkembangan motoriknya yang bisa diaplikasikan dalam aktivitas sehari-hari ataupun untuk olahraga prestasi.

Hal ini diperkuat dengan adanya pengamatan pelaksanaan pembelajaran pendidikan jasmani olahraga dan kesehatan di SD Negeri Andonosari 1 kelas IV, dari hasil pengamatan awal sebagian besar siswa kelas IV SD Negeri Andonosari 1 belum pernah mengikuti tes lari 30 meter, lompat jauh tanpa awalan dan loncat tegak (vertical jump) dan dari hasil pengamatan awal dapat dikatakan semua siswa kelas IV SD Negeri Andonosari 1 belum pernah mengikuti tes lempar tangkap bola dan lempar bola ke dalam gawang menggunakan sasaran.

Pembelajaran pendidikan jasmani di sekolah dasar (SD) bukan mengajarkan cabang olahraga tertentu kepada siswa, melainkan meningkatkan gerak dasar fundamental yang telah dimiliki siswa melalui cabang olahraga tertentu (Fitron \& Mu'arifin, 2020; Rahman, Kurniawan, \& Heynoek, 2020). Pada kenyataannya, selama ini pembelajaran pendidikan jasmani ternyata masih banyak mengacu aspek olahraganya, sehingga dalam pelaksanaannya kegiatan selalu mengacu pada peraturan yang ada sesuai cabang olahraga tertentu, sehingga gerak dasar fundamental yang dimiliki siswa tidak di asah secara optimal. 
Cabang olahraga merupakan salah satu sarana yang dapat dimanfaatkan untuk mencapai tujuan pendidikan jasmani, maka guru pendidikan jasmani harus bisa memodifikasi materi yang akan diberikan sesuai dengan situasi dan kondisi siswa. Tujuan memodifikasi tersebut adalah untuk menyesuaikan kegiatan dengan karakter yang telah dimiliki oleh siswa sebagai untuk mengembangkan baik level kemampuan gerak dasar dan aktifitas siswa untuk membuat pondasi hidup yang aktif dan sehat.

Dari uraian tersebut yang menjadikan latar belakang permasalahan, maka peneliti telah melakukan penelitian dengan judul "Survei Gerak Dasar Lokomotor dan Manipulatif pada Siswa Kelas IV SD Negeri Andonosari 1 Kecamatan Tutur Kabupaten Pasuruan".

Tujuan penelitian ini adalah untuk mengetahui perkembangan gerak dasar lokomotor dan manipulatif siswa melalui tes lari 30 meter, loncat jauh tanpa awalan, loncat tegak, lempar tangkap bola dan lempar bola ke gawang menggunakan sasaran.

\section{METODE}

Penelitian ini menggunakan rancangan penelitian survei. Ditinjau dari tujuan penelitian, penelitian ini termasuk jenis penelitian deskriptif kuantitatif. Penelitian deskriptif adalah penelitian yang dimaksudkan untuk menyelidiki keadaan, kondisi atau hal lain-lain yang sudah disebutkan, yang hasilnya dipaparkan dalam bentuk laporan penelitian (Jamshed, 2014; Leguina, 2015; Marvasti, 2018). Populasi dalam penelitian ini adalah siswa kelas IV SD Negeri Andonosari 1 yang berjumlah 17 siswa, terdiri dari 10 orang laki-laki dan 7 siswi perempuan. teknik pengambilan sampel pada umumnya dilakukan secara random, pengumpulan data menggunakan instrumen penelitian, analisis data bersifat kuantitatif/statistik dengan tujuan untuk menguji hipotesis yang telah diterapkan. Setelah rancangan penelitian tersusun seperti di atas, langkah selanjutnya adalah menentukan variabel yang diteliti (Van Hoecke, 2016).

Instrumen tes menggunakan tes fisik dan tes keterampilan pada usia 10 tahun yaitu tes fisik adalah lari 30 meter, loncat jauh tanpa awalan, loncat tegak (vertical jump) sedangkan tes keterampilan menggunakan tes lempar tangkap bola dan lempar bola ke gawang menggunakan sasaran. Sedangkan instrumen non tes yang digunakan berupa observasi, instrumen non tes bentuk observasi yaitu dengan mengamati pelaksanaan tes fisik dan tes keterampilan pada usia 10 tahun sesuai dengan petunjuk pelaksanaan tes, berupa observasi tes lari 30 meter, tes lompat jauh tanpa awalan, tes loncat tegak (vertical jump) dan tes lempar tangkap bola dan lempar bola ke gawang menggunakan sasaran. Adapun tahap-tahap dalam pengumpulan data meliputi tahap persiapan, tahap pelaksanaan, tahap pelaporan hasil pengumpulan data.

Berdasarkan tujuan penelitian dan dengan pertimbangan jenis data yang diperoleh dari variabel tergantung pada kemampuan gerak dasar lokomotor dan manipulatif, maka prosedur analisis data dilakukan secara manual dengan bantuan kalkulator casio FX 3900 PV.

\section{HASIL}

Berdasarkan hasil analisis data hasil tes lari 30 meter, loncat jauh tanpa awalan, loncat tegak, lempar tangkap bola dan lempar bola ke dalam gawang untuk mengukur gerak dasar lokomotor dan manipulatif dikonversi ke dalam tabel dengan norma khusus dan kriteria tes yang disesuaikan usia peserta diperoleh hasil pada table berikut ini.

Hasil analisis data tes gerak dasar lokomotor dan manipulatif siswa kelas IV SD Negeri Andonosari 1 Kabupaten Pasuruan memperoleh data lari 30 meter modus 6,4 dtk, rata-rata 6,11 dtk, standard deviasi 0,37 $\mathrm{dtk}$, varian $0,13 \mathrm{dtk}$, koefisian varian 6,09 dtk. Data loncat jauh tanpa awalan modus $114 \mathrm{~cm}$, rata-rata 125,2 $\mathrm{cm}$, standard deviasi $17,48 \mathrm{~cm}$, varian $300,5 \mathrm{~cm}$, koefisian varian $13,96 \mathrm{~cm}$. Data loncat tegak modus $25 \mathrm{~cm}$, rata-rata $21,52 \mathrm{~cm}$, standard deviasi $5,96 \mathrm{~cm}$, varian $35,63 \mathrm{~cm}$, koefisian varian $27,72 \mathrm{~cm}$. Data lempar tangkap bola modus 3 kali , rata-rata 2,64 kali, standard deviasi 1,53 kali, varian 2,36 kali, koefisien varian 58,12 kali. data lempar bola ke gawang menggunakan sasaran modus 12 kali, rata-rata 11,41 kali, standard deviasi 2,42 kali, varian 5,88 kali, koefisian varian 21,25 kali. 


\section{PEMBAHASAN}

Berdasarkan data tes kemampuan gerak dasar lokomotor di SD Negeri Andonsari 1 kabupaten Pasuruan dengan hasil rata-rata kelompok tes lari 30 meter untuk siswa laki 6.05 detik dan perempuan 14.42 detik dengan kategori baik untuk siswa laki-laki 6 orang, kategori tidak baik 0 orang dan siswa perempuan kategori baik 6 orang dan kategori tidak baik 0 orang, tes loncat jauh tanpa awalan rata-rata untuk siswa laki-laki 127 $\mathrm{cm}$ dan perempuan $117 \mathrm{~cm}$ dengan kategori baik sekali untuk siswa laki-laki 10 orang, kategori tidak baik 0 orang dan siswa perempuan kategori baik sekali 7 orang, kategori tidak baik 0 orang, tes loncat tegak ratarata untuk siswa laki-laki $23.14 \mathrm{~cm}$ dan siswa perempuan $20.48 \mathrm{~cm}$ dengan kategori baik sekali untuk siswa laki-laki 0 orang, kategori kurang baik 4 orang dan siswa perempuan kategori baik sekali 0 orang dan kategori sedang 4 orang.

Berdasarkan data tes kemampuan gerak dasar manipulatif di SD Negeri Andonsari 1 kabupaten Pasuruan dengan hasil rata-rata kelompok tes tes lempar tangkap bola rata-rata untuk siswa laki-laki 3.42 dan untuk siswa perempuan 2.14 dengan kategori baik sekali untuk siswa laki-laki 0 orang, kategori tidak baik 10 orang dan siswa perempuan kategori baik sekali 0 orang dan kategori tidak baik 7 orang, dan tes lempar bola ke dalam gawang untuk siswa laki-laki 11.85 dan untuk siswa perempuan 10.42 dengan kategori sedang untuk siswa laki-laki 6 orang, kategori tidak baik 0 orang dan siswa perempuan kategori baik sekali 0 orang dan kategori sedang 4 orang.

Pendidikan jasmani di sekolah harus menjadi bagian dari harapan masyarakat dalam rangka memecahkan berbagai penyakit masyarakat sehingga pendidikan jasmani mampu menumbuhkan manusia Indonesia seutuhnya, yang beriman, bertaqwa kepada tuhan yang maha esa, berakhlak mulia, sehat berilmu, cakap, kreatif, mandiri dan menjadi warga Negara yang (Castelli, Centeio, Beighle, Carson, \& Nicksic, 2014; Metzler, 2017). Bagi semua orang dewasa gerakan dapat di lakukan dengan mudah, tetapi tidak dengan demikian halnya dengan siswa sekolah dasar. Dalam hal ini perlu banyak melakukan latihan dan bimbingan dari orang yang lebih dewasa agar lebih mempu untuk melakukan gerakan-gerakan secara teratur melalui kegiatan bermain. Sumantri (2012:27) menyatakan bahwa pada dewasa ini latihan fisik bagi anak-anak sangat baik jika dibandingkan dengan tahun 1960-an. Jantung dan paru-paru mereka bentuknya kurang baik di bandingkan dengan anak-anak yang suka berolahraga daripada anak-anak usia pertengahan tahun. Karakteristik yang kedua dari anak usia SD adalah senang bergerak (Aguirre \& Villareal, 2015; Roy, 2013). Oleh karena itu, guru hendaknya merancang model pembelajaran yang memungkinkan anak aktif bergerak.

Hasil yang diperoleh cenderung pada siswa laki-laki. Anak laki-laki lebih baik kecepatan larinya karena pada usia 6-10 tahun lebih berminat pada olahraga. Seperti halnya memperkenalkan olahraga pada anak laki-laki cenderung lebih senang dengan aktifitas olahraga, hal ini berpengaruh terhadap kemapuan gerak setiap siswa. Krakauer et al. (2019) menyatakan pada dasarnya gerak diperlukan dalam banyak hal, misalnya gerak berlari merupakan keterampilan yang bersifat perkembangan, sehingga semua siswa-siswa bisa menguasainya sebagai akibat kesiapan bersifat maturasi dan komdisi lingkungan yang mendorong perkembangan mereka. Pembelajaran keterampilan gerak mempunyai banyak aspek yang unik, pendekatan untuk belajar gerak sebagian besar masih konsisten dengan teori belajar pada umumnya.

Cara yang bermanfaat untuk menggambarkan bagaimana suatu keterampilan gerak dapat dipelajari secara aktual olehseseorang harus melalui tiga tahap sebelum mereka dapat menguasai suatu gerakan terampil $(\mathrm{Wu}$, Miyamoto, Castro, Ölveczky, \& Smith, 2014). (1) Fase pertama dalam belajar keterampilan gerak disebut fase kognitif, karena pada tahap ini siswa sangat terfokus pada pemrosesan bagaimana gerakan harus dilakukan. Seringkali siswa pemula di tahap initeramati dari mulutnya yang berkonsentrasi penuh atas apa yang mereka lakukan atau sepenuhnya terlupa atas apa yang terjadi di sekitarnya ketika mereka sedang mencobamemilih apa yang harus mereka perbuat untuk menampilkan suatu gerakan. (2) Fase kedua dalam belajar keerampilan gerak disebut fase asosiatif, pada tahap proses belajar ini, siswa bias lebih berkonsentrasi pada suatu dinamika keterampilan, penguasaan timing, keterampilan dan kordinasi gerakan dari bagian-bagian keterampilan untuk menghasilkan kelancaran dan kehalusan gerakan. (3) Fase ketiga dalam belajar keterampilan gerak disebut fase otomatis, pada fase ini siswa tidak berkonsentrasi pada suatu keterampilan. Pemrosesan telah berpindah ke pusat otak lebih bawah, dimana siswa bebas berkonsentrasi pada suatu yang lain, reapon gerakan tidak memerlukan perhatian dari siswa.

Berdasarkan beberapa pendapat di atas, dapat disimpulkan bahwa hasil ketegori tes di sekolah SD Negeri Andonosari 1 kabupaten Pasuruan berada pada kategori baik sekali pada tes lari 30 meter dan berada pada 
kategori kurang sekali pada tes lempar tangkap. Kesimpulan ini dapat diperkuat dengan beberapa faktor yang mempengaruhi siswa seperti halnya lingkungan hidup, makanan, dan kegiatan yang dilakukan setiap harinya.

Berdasarkan beberapa pendapat di atas, dapat disimpulkan bahwa hasil ketegori tes di sekolah SD Negeri Andonosari 1 kabupaten Pasuruan berada pada kategori baik sekali pada tes lari 30 meter dan berada pada kategori kurang sekali pada tes lempar tangkap. Kesimpulan ini dapat diperkuat dengan beberapa faktor yang mempengaruhi siswa seperti halnya lingkungan hidup, makanan, dan kegiatan yang dilakukan setiap harinya.

Setelah para siswa berkembang ketepatan pola geraknya dan gerakan dasar lokomotor dan manipulatif merekapun dapat menggunakanya dengan lebih banyak lagi informasi ahan dari guru sewaktu mereka sedang mencoba untuk memperhalus dan mengkordinasikan aspek-aspek suatu gerakan. Menambah tekanan secara perlahan-lahan seperti dalam hal timing, kecepatan, tenaga, arah, posisi tangan menjadi lebih baik untuk keterampilan kompleks, para siswa berada dalam fase ini dalam waktu yang lama dan sering kembali lagi ke fase ini sekalipun taraf keterampilan tinggi telah berkembang. Siswa dapat lebih menekankan pada suatu aspek atau bagian keterampilan dan masih tetap dapat melakukan bagian-bagiannya tanpa perhatian yang berlebihan. Siswa juga dapat mulai berkonsentrasi pada hal-hal selain keterampilan sehingga guru dapat mulai secara bertahap meningkatkan kompleksitas kondisi latihan, atau misalanya dengan penambahan keterampilan lain.

Perbedaan kemampuan terutama terjadi karena kualitas fisik yang berbeda-beda, dan perbedaan kualitas fisik terjadi karena pengalaman yang berbeda-beda. Setiap peserta didik tidak ada makan makanan yang sama, tidak ada yang melakukan aktifitas dengan kondisi yang sama, tidak ada yang beristirahat dengan kondisi yang sama dan sebagainya. Kondisi yang unik pada setiap peserta didik mengakibatkan terjadinya kemampuan yang berbeda-beda, perbedaan individu bukan hanya yang berkaitan dengan unsur fisik, tetapi juga dalam aspek psikologis. Tidak ada satupun peserta didik yang sama dalam mempunyai watak atau sifat kepribadian dan tingkat kecerdasan dengan peserta didik lain, yang ada hanya kemiripan dan bukan sama persis satu dengan yang lainnya (Cameron et al., 2012; Davis-Dusenbery, Williams, Klim, \& Eggan, 2014).

Dengan kenyataan bahwa tidak seorangpun peserta didik yang sama satu dengan yang lainya baik aspek fisik ataupun psikologis. Maka pada dasarnya setiap orang memerlukan perlakuan yang berbeda-beda di dalam proses pembelajaran agar masing-masing dapat mencapai hasil yang optimal sesuai dengan potensi yang dimiliki.

Pembelajaran pendidikan jasmani bersifat unik, dimana aktifitas yang dilakukan bersama-sama oleh siswa dapat direspondan diketahui secara berbeda-beda ole setiap siswa dan setiap siswa memiliki karakter yang berbeda.

\section{KESIMPULAN}

Berdasarkan rumusan masalah, tujuan dan pembahasan hasil penelitian bab sebelumnya, maka kesimpulan hasil penelitian survei gerak dasar lokomotor dan manipulatif siswa kelas IV SD Negeri Andonosari 1 Kabupaten Pasuruan sebagai berikut. Hasil tes Gerak Lari 30 Meter, Loncat Jauh Tanpa Awalan dan Loncat Tegak (vertical jump) Berdasarkan penelitian yang telah dilakukan pada siswa kelas IV SD Negeri Andonosari 1 Kabupaten Pasuruan telah didapatkan hasil kemampuan gerak lari 30 meter berada pada kategori baik sebesar $71 \%$ (12 siswa) dan kategori tidak baik 0\% (tidak ada siswa). Kemampuan gerak loncat jauh tanpa awalan berada pada kategori baik sekali sebesar 100\% (17 siswa) dan kategori tidak baik sebesar 0\% (tidak ada siswa) dan kemampuan gerak loncat tegak (vertical jump) berada pada kategori sedang dan kurang baik sebesar 41\% (14 siswa) dan kategori tidak baik sebesar 6\% (1 siswa). Hasil tes Gerak Lempar Tangkap Bola dan Lempar Bola ke Gawang Menggunakan Sasaran. Berdasarkan penelitian yang telah dilakukan pada siswa kelas IV SD Negeri Andonosari 1 Kabupaten Pasuruan telah didapatkan hasil kemampuan gerak lempar tangkap bola berada pada kategori baik sekali sebesar 0\% (tidak ada siswa) dan kategori tidak baik 100\% (17 siswa). Kemampuan lempar bola ke gawang menggunakan sasaran berada pada kategori sedang sebesar 59\% (10 siswa) dan kategori tidak baik 0\% (tidak ada siswa).

\section{DAFTAR PUSTAKA}

Aguirre, L. E., \& Villareal, D. T. (2015). Physical Exercise as Therapy for Frailty. Nestle Nutrition Institute 
Workshop Series. https://doi.org/10.1159/000382065

Cameron, C. E., Brock, L. L., Murrah, W. M., Bell, L. H., Worzalla, S. L., Grissmer, D., \& Morrison, F. J. (2012). Fine Motor Skills and Executive Function Both Contribute to Kindergarten Achievement. Child Development. https://doi.org/10.1111/j.1467-8624.2012.01768.x

Castelli, D. M., Centeio, E. E., Beighle, A. E., Carson, R. L., \& Nicksic, H. M. (2014). Physical literacy and Comprehensive School Physical Activity Programs. Preventive Medicine. https://doi.org/10.1016/j.ypmed.2014.06.007

Davis-Dusenbery, B. N., Williams, L. A., Klim, J. R., \& Eggan, K. (2014). How to make spinal motor neurons. Development (Cambridge). https://doi.org/10.1242/dev.097410

Department for Education. (2013). Physical education programmes of study: key stages 3 and 4 National curriculum in England Purpose of study. London: DfE. https://doi.org/FE-00190-2013

Fitron, M., \& Mu'arifin. (2020). Survei Tingkat Persepsi Siswa Terhadap Konsep Pendidikan Jasmani Di Sekolah Menengah Atas. Sport Science and Health, 2(5), 264-271. Retrieved from http://journal2.um.ac.id/index.php/jfik/article/view/11794/5767

Habe, H., \& Ahiruddin, A. (2017). Sistem Pendidikan Nasional. Ekombis Sains: Jurnal Ekonomi, Keuangan Dan Bisnis. https://doi.org/10.24967/ekombis.v2i1.48

Jamshed, S. (2014). Qualitative research method-interviewing and observation. Journal of Basic and Clinical Pharmacy. https://doi.org/10.4103/0976-0105.141942

KEMENKES. (2014). Jaminan Kesehatan Nasional. Www.Jkn.Kemkes.Go.Id.

Krakauer, J. W., Hadjiosif, A. M., Xu, J., Wong, A. L., \& Haith, A. M. (2019). Motor learning. Comprehensive Physiology. https://doi.org/10.1002/cphy.c170043

Leguina, A. (2015). A primer on partial least squares structural equation modeling (PLS-SEM). International Journal of Research \& Method in Education. https://doi.org/10.1080/1743727x.2015.1005806

Marvasti, A. (2018). Research methods. In The Cambridge Handbook of Social Problems. https://doi.org/10.1017/9781108656184.003

McKenzie, I. A., Ohayon, D., Li, H., De Faria, J. P., Emery, B., Tohyama, K., \& Richardson, W. D. (2014). Motor skill learning requires active central myelination. Science. https://doi.org/10.1126/science.1254960

Metzler, M. (2017). Instructional Models in Physical Education. In Instructional Models in Physical Education. https://doi.org/10.4324/9781315213521

Mu'arifin, Kurniawan, A. W., \& Heynoek, F. (2018). Developing Professional Development Model For Physical Education, Sports, And Health Primary School Teachers In Learning Organizing. Journal of Indonesian Physical Education and Sport, 4(2), 79-87.

Pendidikan Nasional. (2014). Peraturan Menteri Pendidikan Dan Kebudayaan Republik Indonesia Nomor 103 Tahun 2014 Tentang Pembelajaran Pada Pendidikan Dasar Dan Pendidikan Menengah. In Implementation Science. https://doi.org/10.4324/9781315853178

Rahman, Z., Kurniawan, A. W., \& Heynoek, F. P. (2020). Pengembangan Pembelajaran Kebugaran Jasmani Unsur Kecepatan Berbasis Multimedia Interaktif. Sport Science and Health, 2(1), 78-92. Retrieved from http://journal2.um.ac.id/index.php/jik/article/view/11692/5123

Roy, B. A. (2013). High-Intensity Interval Training. ACSM's Health \& Fitness Journal. https://doi.org/10.1249/fit.0b013e31828cb21c

Van Hoecke, M. (2016). Methodology of Comparative Legal Research. Law and Method. https://doi.org/10.5553/rem/.000010

Wallhead, T. L., \& Ntoumanis, N. (2016). Effects of a Sport Education Intervention on Students' Motivational Responses in Physical Education. Journal of Teaching in Physical Education. https://doi.org/10.1123/jpe.23.1.4

Wu, H. G., Miyamoto, Y. R., Castro, L. N. G., Ölveczky, B. P., \& Smith, M. A. (2014). Temporal structure of 
motor variability is dynamically regulated and predicts motor learning ability. Nature Neuroscience. https://doi.org/10.1038/nn.3616 